
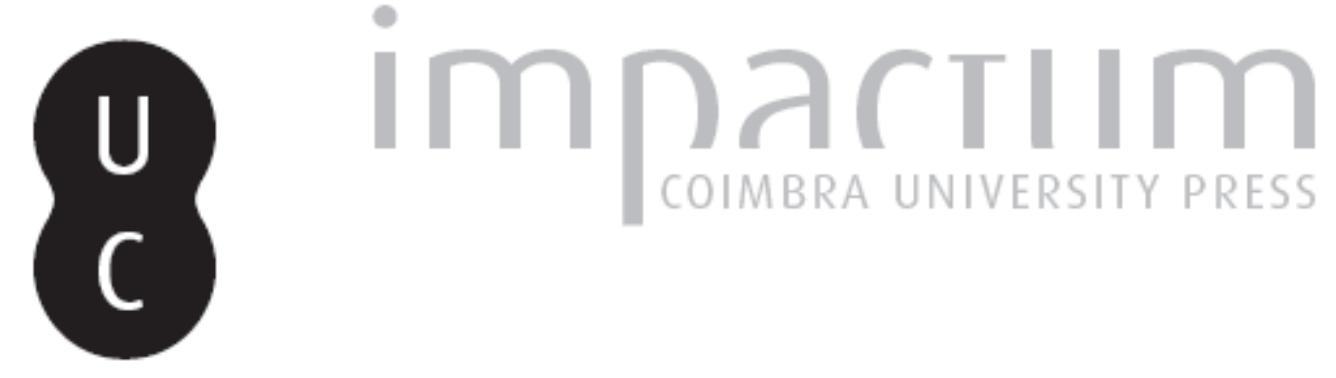

\title{
[Recensão a] Futurismo Avanguardia Avanguardie, a cura di Didier Ottinger; Futurismo 1909-2009 Velocità + Arte + Azione, a cura di Giovanni Lista e Ada Masoero
}
Autor(es):
Marnoto, Rita

Publicado por: Imprensa da Universidade de Coimbra

URL

persistente:

URI:http://hdl.handle.net/10316.2/42589

DOI:

DOI:https://doi.org/10.14195/0870-8584_4_18

Accessed : $\quad$ 26-Apr-2023 11:58:05

A navegação consulta e descarregamento dos títulos inseridos nas Bibliotecas Digitais UC Digitalis, UC Pombalina e UC Impactum, pressupõem a aceitação plena e sem reservas dos Termos e Condições de Uso destas Bibliotecas Digitais, disponíveis em https://digitalis.uc.pt/pt-pt/termos.

Conforme exposto nos referidos Termos e Condições de Uso, o descarregamento de títulos de acesso restrito requer uma licença válida de autorização devendo o utilizador aceder ao(s) documento(s) a partir de um endereço de IP da instituição detentora da supramencionada licença.

Ao utilizador é apenas permitido o descarregamento para uso pessoal, pelo que o emprego do(s) título(s) descarregado(s) para outro fim, designadamente comercial, carece de autorização do respetivo autor ou editor da obra.

Na medida em que todas as obras da UC Digitalis se encontram protegidas pelo Código do Direito de Autor e Direitos Conexos e demais legislação aplicável, toda a cópia, parcial ou total, deste documento, nos casos em que é legalmente admitida, deverá conter ou fazer-se acompanhar por este aviso.

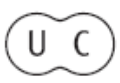




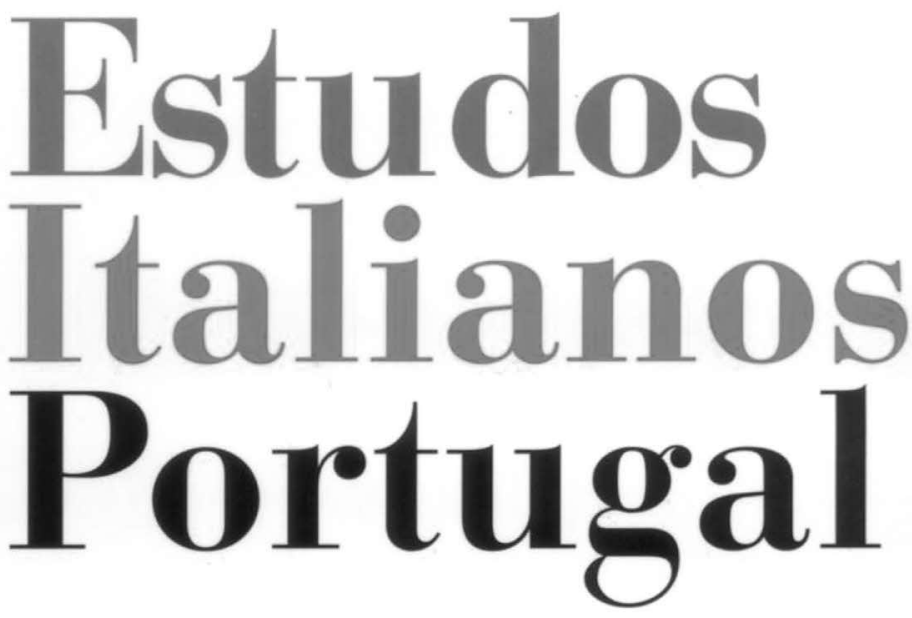

Instituto

Italiano

de Cultura

de Lisboa

Nova Série

$\mathbf{N}^{\mathbf{0}} 4$.

2009 
dá sobejas provas das suas capacidades de filóloga e de investigadora, que tentou juntar e explicar todos os materiais pré-textuais e para-textuais ("autógrafos, ideógrafos, provas de impressão", "diários, correspondência, biografias, etc.”), não desprezando nenhum "testemunho", exibindo até 23 facsímiles de inéditos, e detendo-se depois na análise minuciosa das variantes.

O escrúpulo da estudiosa que andou por espólios, bibliotecas, entrevistas, e que valorizou rascunhos, borrões, provas, fragmentos, vê-se também nas anotações minuciosas e no esforço para apresentar e sinalizar o texto regiano e as suas variantes com a máxima clareza, num bonito modelo e aparato gráfico que definiu por certo em diálogo com os responsáveis das Edições Quasi.

No final, não será dificil ao leitor acompanhar as conclusões de Maria Bochicchio sobre a "psicologia da composição” de Régio, sobre a tipologia das suas variantes, sobre as suas opções estético-literárias. Mas também não será difícil ao leitor reconhecer os muitos méritos desta nova lusófila italiana. Régio confessou um dia “a um jovem poeta": ”Já te dei tudo quanto posso". Maria Bochicchio despendeu neste seu fecundo e modelar trabalho muita energia investigadora e analítica; por ele intuímos que ela tem ainda muito e muito valioso a dar não só a Régio mas também à poesia, à cultura e à língua portuguesa que tanto ama - e que desde já lhe deve estar reconhecida. ARNALDO SARAIVA

\section{Futurismo Avanguardia Avanguar-} die, a cura di Didier Ottinger, $\mathrm{Pa}-$ rigi, Centre Georges Pompidou, Milano, 5 Continents Éditions, 2009, 359 pp.

\section{Futurismo 1909-2009 Velocità +} Arte + Azione, a cura di Giovanni Lista e Ada Masoero, Milano, Skira, 2009, 451 pp. + CD

Se o lastro e a memória de uma exposição perduram através das páginas do seu catálogo, boa parte da mais recente história crítica sobre o Futurismo, nas suas valências europeias e internacionais, está ligada à concepção de uma célebre mostra, que remonta a 1986, e cujo catálogo constitui uma referência para os estudiosos da matéria. Refiro-me a $\mathrm{Fu}$ turismo e Futurismi. Catalogo della mostra, Venezia, Palazzo Grassi 
(a cura di Pontus Hulten, Milano, Bompiani, 1986, 1992). Note-se que o Futurismo, enquanto primeira grande vanguarda que cruzou domínios artísticos diversificados, fazendo da escrita um espectáculo onde a visualidade ocupa um lugar primordial, está intrinsecamente vocacionado para a exposição. Não surpreende, pois, que, no ano do centenário do Manifesto de fundação do Futurismo, a conjunção de mostra e catálogo seja uma dupla privilegiada pelas entidades que se propõem celebrar o evento, projectando-o para além da mera efeméride.

Os dois catálogos que aqui se assinalam acompanham duas grandes exposições sobre o $\mathrm{Fu}$ turismo.

A primeira, de Roma, é produto da colaboração entre as Scuderie del Quirinale, o Centre Georges Pompidou de Paris e a Tate Modern de Londres. Parte de uma ideia-base, o primordial papel desempenhado pelo Futurismo no quadro das vanguardas de início de século, a qual é depois declinada, de modo específico, por cada uma dessas instituições, onde a mostra é sucessivamente acolhida, em Paris, em Roma e em Londres. Ao ser montada, em cada uma destas cidades, é alvo de adaptações de perspectiva específicas, numa dimensão internacionalista.

Nas páginas iniciais do catálogo, a primeira imagem marcante é o panfleto que anuncia a exposição dos pintores futuristas apresentada na galeria Bernheim-Jeune, de Paris, no ano de 1912. As suas telas logo se distinguem pelo modo como decompõem estratos e formas, sem que inscrevam uma instância analítica, mas antes jogando com o dinamismo de planos e linhas, pelo que se distanciam dos trilhos do cubismo. A partir daí, são ilustradas as várias modalidades expressivas que vão tomando forma no seio do movimento, bem como o percurso que, do Futurismo italiano, leva ao cubo-futurismo russo, ao vorticismo inglês ou ao sincronismo americano.

A segunda mostra, a de Milão, foi organizada pela Autarquia desta cidade e está patente no Palazzo Reale. Visa documentar os vários aspectos do programa futurista, considerando Milão como o seu berço. Acompanha as várias facetas do seu desenvolvimento histórico, evidenciando o propósito de renovar radical- 
mente toda a vida quotidiana, numa dimensão que se aproxima da utopia. Ao contrário da exposição de Roma, que concentra obras de pintura e escultura, a de Milão inclui também desenhos, tábuas de palavras-livres, projectos e esquissos arquitectónicos, cenografias, desenhos e guarda-roupa de cena, fotografias e objectos vários.

Ambos os catálogos, na sua estrutura, cruzam uma dimensão sintagmática com uma dimensão paradigmática.

Futurismo Avanguardia Avanguardie inclui uma secção de textos críticos, à qual se segue uma compilação das obras expostas nas várias mostras, com reprodução ilustrada e nota explicativa para cada uma delas. Termina com um aparato formado por uma cronologia do Futurismo, uma lista das obras em exposição e uma bibliografia. Os textos críticos são de autoria de Didier Ottinger, Giovanni Lista, que tem uma intervenção de destaque nos dois catálogos, Ester Cohen, Jean-Marie Marcadé e Matthew Gale.

Um dos temas tratados por Giovanni Lista diz respeito à génese do Manifesto de fundação do Futurismo, que é dilucidada atra- vés de novos contributos. Apesar de a génese do manifesto andar associada, no entender deste crítico, ao desastre de automóvel que Marinetti teve em Outubro de 1908, o líder do Futurismo teria achado mais oportuno protelar a sua divulgação para o início de 1909. Publica-o, no entanto, em versão integral, como texto de abertura de dois livros editados em 1908: Le ranocchie turchine de Cavacchioli e a antologia Enquête internationale sur le vers libre. Além disso, manda imprimir milhares folhas volantes com os pontos programáticos do manifesto, impressos a azul, com uma tiragem em italiano e outra em francês. Prepara, entretanto, a publicação do Manifesto de fundação do Futurismo no número da revista Poesia de Dezembro de 1908-Janeiro 1909. Acabará por não sair. $\mathrm{O}$ terramoto que a 28 de Dezembro abala Messina choca a Itália, e nas páginas que estavam reservadas à sua edição sai um poema de Lucini dedicado às vítimas da catástrofe. Mas a partir do momento em que os manifestos começam a ser distribuídos, no final de Janeiro, logo é referido e publicado, integral ou parcialmente, em vários jor- 
nais italianos, embora Giovanni Lista ponha em destaque a edição integral que dele é feita por La Gazetta d'Emilia, de Bolonha, a 5 de Fevereiro. Se a edição de Le Figaro, a 20 de Fevereiro de 1909, foi a que deu ressonância internacional ao Manifesto de fundação do Futurismo, não foi essa, em rigor, a primeira.

O catálogo Futurismo 1909-2009 Velocità + Arte + Azione, por sua vez, divide-se em várias secções constituídas por um texto crítico e por ilustrações que lhe são correlatas. Os textos são de autoria de Giovanni Lista, Ada Masoero, Maurizio Calvesi, Fred Licht, Daniele Lombardi e Valerio Terraroli. Desenvolvem núcleos temáticos da exposição, assim recobrindo domínios artísticos que vão da pintura à escultura, à literatura, ao cinema, à fotografia, à arte dos rumores, à arquitectura, ao teatro e às artes decorativas. É acompanhado de um CD.

$\mathrm{Na}$ intervenção que dedica à arquitectura, Giovanni Lista, autor de grande parte dos textos, põe em evidência o carácter unitário da poética futurista, através de um percurso evolutivo que vai até Sant'Elia, Virgilio Marchi,
Alberto Sartoris, Filia, Quirino De Giorgio, etc., e que tem a particularidade de correlacionar arquitectura, literatura, pintura, escultura. Já na recolha de poemas que Marinetti publica em 1908, La ville charnelle, fica patente o seu distanciamento do olhar decadente sobre a cidade, em prol do novo ritmo marcado pela velocidade do automóvel e pela energia das multidões. A partir daí, a arte identifica-se não só com o processo de industrialização, como também com as grandes massas e os grandes volumes de betão. Boccioni trata o tema nas suas telas, nomeadamente em La città che sale, mas é no Manifesto técnico da escultura futurista que fundamenta uma escultura com base arquitectónica. Centra a funcionalidade da arquitectura num dinamismo plástico que encontra na espiral o seu arquétipo, recusando os modelos geométricos do passado, ideias que retomará em $A$ arquitectura futurista. É então que irrompe a polémica com Balla, a qual acaba por abrir espaço para o ingresso de um grupo de jovens arquitectos, de entre os quais se distingue Sant'Elia. O autor do Manifesto da arquitectura futurista, de 1914, 
é um arquitecto por formação. Conhece bem a construção, sabendo, como tal, que nesse capítulo não é possível fazer tábua rasa das lições tiradas do passado. No entanto, advoga a total libertação dos estilos históricos em voga. Por essa via, procede a uma inversão de rota, na medida em que não se propõe partir da tecnologia para renovar a arquitectura, mas conceber formas arquitectónicas a partir da tecnologia, conferindo à arquitectura a função.

Estamos, pois, perante dois catálogos que, pela clareza organizativa, pela qualidade da reprodução das ilustrações, pelo teor dos textos publicados, os quais, sem deixarem de ser acessíveis, desbravam novos domínios críticos, são apostas de fundo. Deve, porém, ser salientado que, apesar de essa expansão de campo poder traduzir o alargamento do público que se interessa pela arte de vanguarda, assim correspondendo ao desideratum de Marinetti, é a hegemonia mediática que a comanda.

Em vão poderão ser procuradas referências, nas páginas dos catálogos, a um Amadeu de Sousa Cardoso ou a um Almada Ne- greiros, o que mostra a posição periférica que é reservada à vanguarda portuguesa. RITA MARNOTO

Giusi Baldissone, Filippo Tommaso Marinetti, Milano, Mursia, 2009, 297 pp.

Convirá assinalar, à partida, que a monografia de Giusi Baldissone não se integra naquela categoria de obras que surpreende o público pela apresentação de uma tese bizarra ou inaudita. $\mathrm{Na}$ verdade, a história editorial de Filippo Tommaso Marinetti estende-se ao longo de duas décadas. Saiu pela primeira vez em 1986, foi reimpressa, e a edição de 2009 é revista e actualizada. Quer isto dizer que se trata de um volume que leva a chancela do tempo, na medida em que nele confluem experiências de organização cultural, pesquisas documentais e aprofundamentos críticos que foram sendo joeirados, ampliados e maturados ao longo dos anos. Recorde-se que Giusi Baldissone colaborou na grande exposição que no presente ano foi dedicada ao líder do Futurismo italiano pela Fondazione Stelline, de Milão. 